\title{
As cores da bandeira brasileira em diferentes cenários de iluminação ${ }^{+*}$
}

\section{Linizia Ferreira da Silva ${ }^{1}$}

Bolsista do Programa de Educação Tutorial da Licenciatura em Física

Raimundo Nonato de Medeiros Júnior ${ }^{2}$

Instituto Federal de Educação, Ciência e Tecnologia do Rio Grande do Norte

Campus João Câmara

João Câmara - RN

\section{Resumo}

Objetivando esclarecer conceitos relativos à Óptica e suas metodologias de ensino, sobretudo, acerca da percepção dos objetos quando iluminados com fontes de luz em determinadas cores ou faixas do espectro luminoso, desenvolveu-se uma análise centrada na problemática da percepção visual das cores da bandeira brasileira, considerando diferentes cenários de iluminação. Essa questão, habitualmente aplicada no cotidiano dos docentes, apresentou respostas conflitantes em algumas ferramentas relevantes no ensino-aprendizagem da Física. As ferramentas, pelas quais foram obtidos tais resultados, contemplam livros didáticos da disciplina de Física do Ensino Médio; uma das provas de seleção do Mestrado Nacional Profissional em Ensino de Física - MNPEF (2015), da Sociedade Brasileira de Física - SBF; bem como, simulações digitais concebidas no software Cores - Óptica, pertencente ao projeto Acessa Física. Como proposição para dirimir as dúvidas identificadas durante a comparação desses recursos, no contexto do Programa de Educação Tutorial - PET, adotou-se a experimentação, por meio de uma prática com materiais simples e acessíveis. Os resultados demonstraram a importância dos experimentos, como forma de elucidar conceitos contundentes, aprofundando a análise da questão discutida e promovendo uma nova perspectiva para o estudo das cores.

\footnotetext{
+ The colors of the brazilian flag in different lighting scenarios

* Recebido: novembro de 2016.

Aceito: maio de 2017.

1 E-mail: leniziasilva@gmail.com

2 E-mail: nonato.junior@ifrn.edu.br
} 
Palavras-chave: Bandeira Brasileira; Estudo das Cores; Experimentação; Materiais Acessíveis; Óptica; Simulações.

\begin{abstract}
Aiming to clarify concepts related to Optics and its teaching methodologies, above all on the perception of objects when illuminated with light sources in certain colors or bands of the light spectrum, an analysis was developed focusing on the problem of visual perception of Brazilian flag colors, considering diferente lighting scenarios. This question, usually applied in the teachers' daily routine, has presented conflicting answers in some relevant tools in the teaching-learning of Physics. The tools, in which were obtained such results, contemplate didactic books of the discipline of Physics of High School; One of the selection tests of the Mestrado Nacional Profissional em Ensino de Física-MNPEF (2015), from Sociedade Brasileira de Física-SBF; As well as, digital simulations conceived in the software Cores-Óptica, belonging to the project Acessa Física. As a proposal to solve the doubts identified during the comparison of these resources, in the context of the Programa de Educação Tutorial-PET, the experimentation was adopted, through a practice with simple and accessible materials. The results demonstrated the importance of the experiments, as a way of elucidating conflicting concepts, deepening the analysis of the discussed and promoting a new perspective for the study of colors.
\end{abstract}

Keywords: Brazilian Flag; Study of Colors; Experimentation; Affordable Materials; Optics; Simulations.

\title{
I. Introdução
}

A escolha do tema se deu a partir da compreensão de que o estudo das cores é pouco explorado dentro do ensino da Óptica. Em uma breve investigação no material consultado, desenvolvida no contexto do Programa de Educação Tutorial - PET, do IFRN campus João Câmara, detectou-se divergências nas respostas a questões pertinentes à percepção das cores, principalmente, em relação ao visual das cores da bandeira do Brasil em diferentes cenários de iluminação.

A motivação surgiu ao comparar-se as respostas apresentadas a essa problemática em variados veículos de ensino-aprendizagem, adotados comumente pelos docentes da disciplina de Física. Foi possível perceber que a questão da percepção visual das cores da bandeira brasileira demonstrou diferentes entendimentos quando comparadas as discussões existentes em 
livros de Física do Nível Médio, com os resultados obtidos pelo Software Cores - Óptica, pertencente ao projeto Acessa Física.

Como a simulação neste aplicativo limita-se a apresentar apenas as luzes e os pigmentos primários, fez-se necessária a busca por outra fonte para a comparação das respostas em relação às cores e pigmentos secundários. Nesse caso, adotou-se a compreensão apontada pelos elaboradores de uma das questões incluídas na prova de seleção para o Mestrado Nacional Profissional em Ensino de Física - MNPEF, da Sociedade Brasileira de Física - SBF, aplicado em 2015. Considerando a analogia entre as questões tratadas, novamente foram confrontadas as expectativas ligadas à percepção das cores da bandeira brasileira, conforme a exposição às variadas fontes de iluminação, e as respostas encontradas foram mais uma vez conflitantes.

Na compreensão de Borges e Morais (1998 apud Silva 2013, p. 126): “experimentar [...] é submeter à experiência; é por à prova; é ensaiar; é conhecer ou avaliar pela experiência". Desse modo, com o objetivo de minimizar as dúvidas sobre as respostas e as explicações apresentadas pelas bases analisadas, optou-se por verificar, através de experimentos simples e materiais acessíveis, como se apresenta visualmente a bandeira do Brasil, quando iluminada exclusivamente com luzes nas cores verde (experimento I), vermelho (experimento II) e amarelo (experimento III), respectivamente, e, finalmente, apontar qual das situações apresentadas na investigação se assemelha à realidade identificada na fase de experimentação, possibilitando elucidar, de forma adequada, a problemática abordada, e demonstrar o valor da experimentação para a ciência e para o ensino de ciências.

\section{A ciência das cores}

A luz é um fenômeno que seduz a humanidade desde a antiguidade, pois sua compreensão é de extrema importância para a descrição e compreensão de fenômenos observados em nosso cotidiano, como a formação do arco-íris, as cores do pôr do sol, do céu, de uma bolha de sabão ou de qualquer objeto. Estes podem ser explicados através dos princípios da reflexão e absorção, da refração dos raios de luz e pelo fenômeno da difração e interferência, incluídos no ramo da Física chamado de Óptica.

Com relação às cores apresentadas pelos objetos, a luz e os pigmentos estão intimamente ligados, uma vez que, para percebermos a cor de um objeto é preciso que este seja iluminado (GREF, 2011). A esse respeito, Halliday, Resnick e Walker (2009), afirmam que a luz visível pode se comportar como fótons quando interage com a matéria, ou ainda, quando se propaga, como um conjunto de ondas eletromagnéticas, cujos comprimentos de onda estão aproximadamente entre 430 nanômetros e 690 nanômetros, e as radiações fora desse intervalo não produzem, em nosso olho, a sensação de visão. 
Dessa maneira, as cores com que os objetos se apresentam correspondem à cor da luz ou à composição de luz que são capazes de refletir difusamente ${ }^{3}$. Quando iluminamos um objeto com luz branca e o enxergamos na cor verde, significa que ele tem a capacidade de refletir a faixa verde do espectro visível e absorver as demais faixas (GREF, 2011). Nesse sentido, as plantas ao receberem radiação solar estão expostas a radiações de diferentes frequência, e, de acordo com a Teoria da Quantização da Energia, estudada pela Física Moderna, à cada frequência está associada uma quantidade de energia, que é transportada pelos fótons da radiação. Segundo Melo Júnior (2015), quando expostas a uma radiação com uma faixa de frequência correspondente a cor verde, as plantas têm prejuízos em seu desenvolvimento, pois a energia dessa radiação não é absorvida, o que remete à sua reflexão e, por isso, enxergamos a maioria das plantas na cor verde.

Entretanto, o que acontece em nosso olho para que possamos enxergar de fato um objeto com determinada cor? Segundo Heneine (2010), o olho humano possui na retina dois tipos de fotorreceptores, - células sensíveis à luz - são os cones e os bastonetes, como mostra a Fig. 1. Os cones são responsáveis pela percepção das cores, e operam sob grande intensidade luminosa. Diferentemente, os bastonetes permitem a percepção de imagens em tons de cinza e operam sob pouca intensidade luminosa.

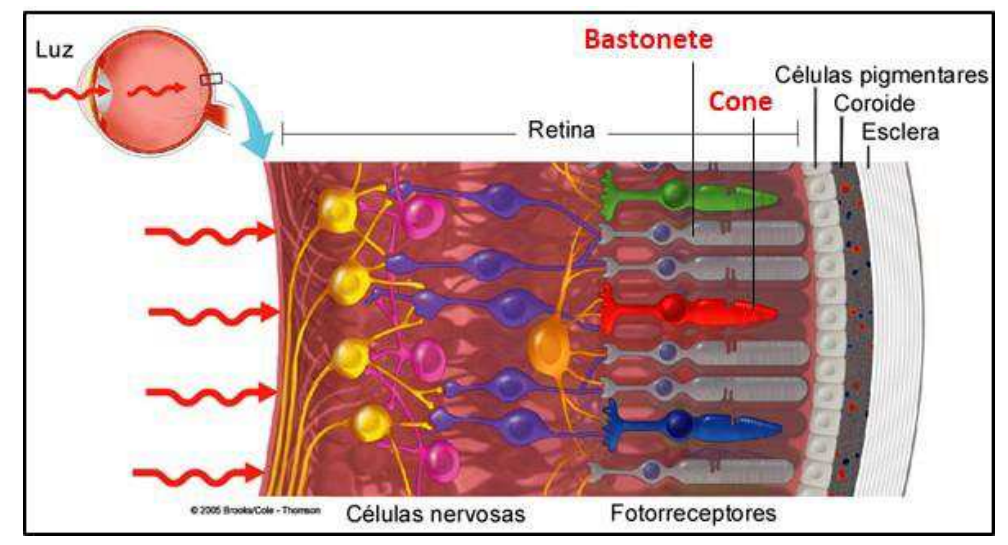

Fig. 1 - Seção reta da retina. Fonte: Nishida, Oliveira, Troll (2008).

Com relação à interpretação dada à coloração dos objetos por nosso cérebro, Okuno, Calda e Chow (1982, p. 273) afirmam que:

[...] os cones nos olhos humanos são sensiveis às cores primárias: azul, verde e vermelho. As cores intermediárias são interpretadas pelo cérebro de acordo com a combinação de respostas dos vários tipos de cones. Por exemplo, a luz amarela estimula os cones sensiveis ao verde e ao vermelho de maneira aproximadamente igual. Assim, quando esses tipos de cones forem estimulados igualmente, o cérebro

\footnotetext{
${ }^{3} \mathrm{~A}$ reflexão difusa ocorre quando os raios de luz são refletidos em várias direções, devido incidirem em uma superfície irregular.
} 
interpreta a cor como amarelo. Se não existirem os cones sensíveis a uma determinada cor ocorre o daltonismo.

Em função disso, a percepção do branco resulta da combinação das luzes vermelha, verde e azul, nas mesmas proporções de intensidade. A Fig. 2a mostra uma ilustração que demonstra quando a intensidade dessas três luzes está em cem por cento. Estas luzes são consideradas primárias, pois, a partir de combinações entre elas (dependendo de suas intensidades) são obtidas luzes nas mais variadas cores. A Fig. 2b registra uma situação em que cada luz possui intensidade diferente.

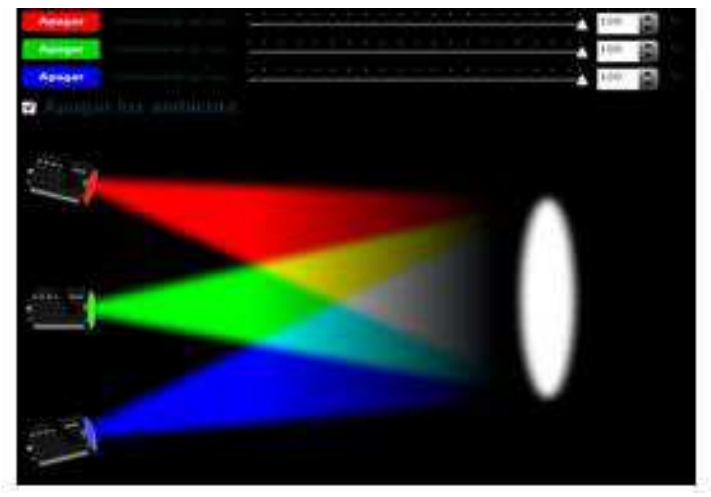

Fig. 2a-Luzes com máxima intensidade.

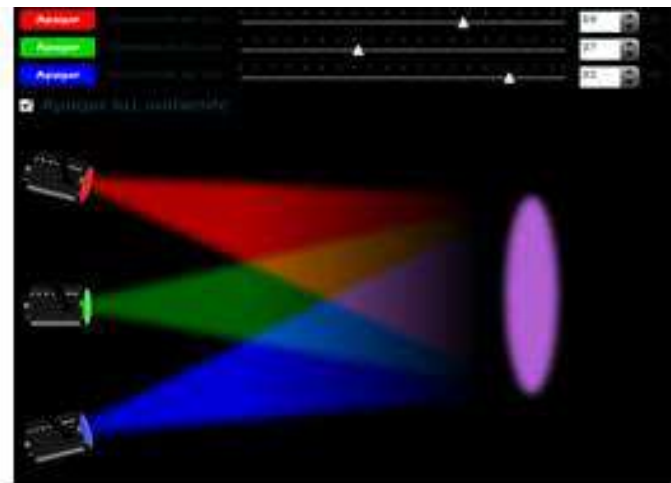

Fig. $2 b$ - Luzes com intensidades variadas.

Fonte: BRASIL (2010) Captura de tela adaptado do software Cores.

Para se distinguir os tipos de cores para luz ou pigmento, respectivamente, foram criados vários sistemas de formação de cores, entretanto, apenas serão apresentados neste texto o sistema RGB (Red, Green e Blue) que, do inglês, correspondem ao vermelho, verde e azul, respectivamente e o CMY (Cyan, Magenta e Yellow) que, em português, contemplam o ciano, magenta e amarelo, nesta ordem.

O sistema RGB utiliza fontes luminosas nas cores vermelho, verde e azul, considerando-as como sendo primárias para formação de cores (luzes). Em outras palavras, promovendo a superposição dessas luzes, na mesma proporção de intensidade luminosa, se obtém as cores (luzes) secundárias - amarelo, ciano e magenta.

Pelo princípio da independência dos raios de luz, os raios que se superpõe não sofrem nenhuma alteração em suas respectivas trajetórias, porém, na intercessão dos desses raios ocorre o processo de adição de luzes ou junção de frequências, que dará origem a uma cor de luz diferente das originais e, portanto, com uma frequência específica, como ilustra a Fig. 3. 


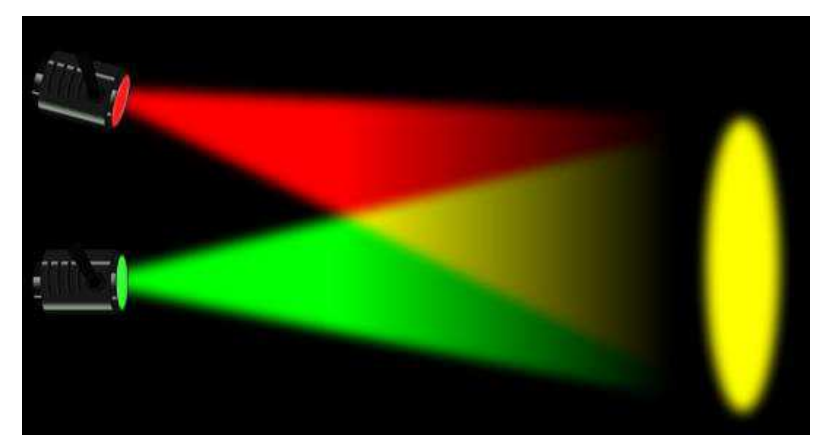

Fig. 3 - Principio da independência dos raios de luz. Fonte: BRASIL (2010) Captura de tela adaptado do software Cores.

O sistema CMY utiliza o ciano, o magenta e o amarelo como cores primárias para formação de pigmentos (tintas). Nesse caso, ocorre à subtração de uma região específica do espectro visível. A esse respeito, GREF (2011, p. 259), explica que "esse processo está presente quando se mistura tintas de cores diferentes, obtendo-se uma cor resultante da interação da luz branca da iluminação com os pigmentos de cor.”.

Estudos mostram que o pigmento amarelo, ao ser iluminado com luz branca, absorve a parte do espectro visível correspondente ao azul e reflete as partes que correspondem ao amarelo, ao verde e ao vermelho, da mesma forma que o pigmento magenta absorve a parte verde, e reflete as partes vermelho e azul do espectro visível. Ainda nas mesmas condições, o pigmento ciano absorve o vermelho e o amarelo e reflete o azul e o verde (GREF, 2011). Contudo, os pigmentos secundários, vermelho, verde e azul, só refletem as cores (luzes) primárias.

\section{Motivação da pesquisa}

A problemática surgiu da percepção de respostas distintas para um mesmo questionamento, - analisado em diferentes veículos - qual seja, o visual da bandeira brasileira quando iluminada com uma luz de cor específica. A primeira análise realizada aponta a abordagem para esta questão nos livros de Física do Ensino Médio; a segunda, desenvolvida com o auxílio de simulações do projeto Acessa Física, através do Software Cores - Óptica; e, finalmente, com base em uma das provas de seleção do Mestrado Nacional Profissional em Ensino de Física - MNPEF, da Sociedade Brasileira de Física - SBF.

Newton, Helou e Gualter (2010) propõem trabalhar o fenômeno das cores a partir da problemática apresentada abaixo, extraída do livro Física, vol. II, página 297: 
A bandeira do Brasil esquematizada na figura é confeccionada em tecidos puramente pigmentados:

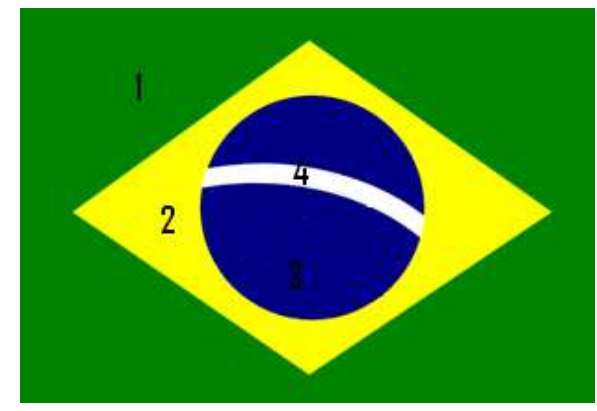

Estando estendida sobre uma mesa no interior de um recinto absolutamente escuro, a bandeira é iluminada por luz monocromática. Determine de que cores serão vistas as regiões designadas por 1, 2, 3 e 4 no caso de:

a) A luz monocromática ser verde;

b) A luz monocromática ser vermelha.

Em sua abordagem, Newton, Helou e Gualter (2010, p. 289) dizem que:

[...] Se "vemos" um corpo preto, é porque ele está absorvendo todas as cores do espectro solar. Um corpo que nos parece vermelho quando iluminado pela luz. branca solar se apresentará escuro quando iluminado por luz monocromática diferente da vermelha (azul, por exemplo).

Seguindo essas definições, a bandeira do Brasil se apresentará como ilustra as Fig. 4a e $4 b$, respectivamente.

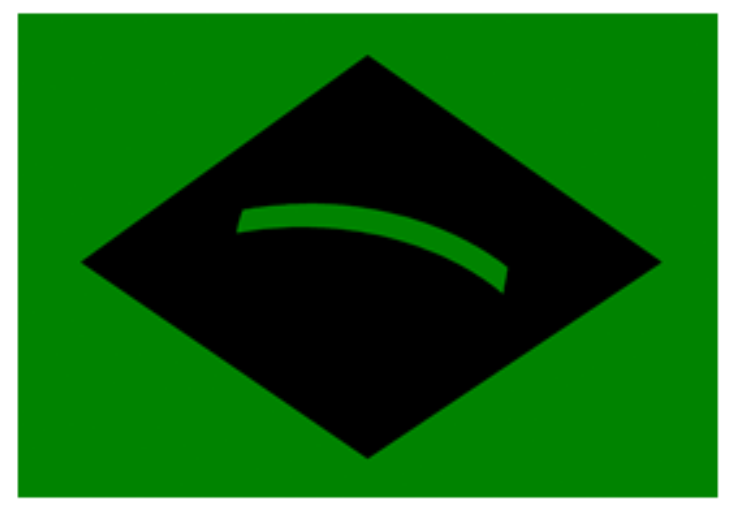

Fig. 4a-Bandeira brasileira iluminada com luz verde.

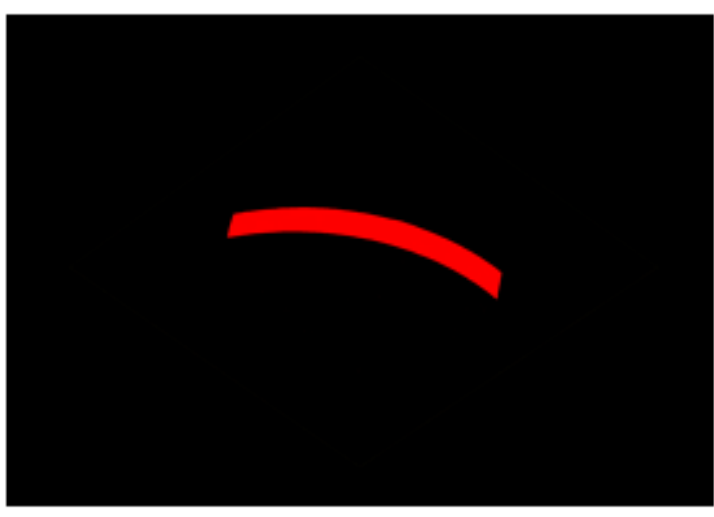

Fig. $4 b$ - Bandeira brasileira iluminada com luz vermelha.

Fonte: Elaborado pelos autores (2016). 
Na abordagem de Máximo e Alvarenga (2011) foi analisada a questão reproduzida a seguir, extraída do livro Curso de Física, vol. 2, página 222.

Suponha que a bandeira do Brasil seja colocada em um quarto escuro e iluminada com luz monocromática amarela. Diga a cor com a qual se apresentarão as partes da bandeira:

a) O círculo central

b) Losango

c) A faixa do círculo central e as estrelas

De acordo com a abordagem adotada por estes autores, a luz amarela é considerada como sendo monocromática, ou seja, "luz de uma só cor" e, por isso, só consegue ser refletida pelas regiões amarela e branca da bandeira. Na porção restante ocorreria apenas a absorção dessa radiação.

Segundo esse conceito, a bandeira brasileira, que sob iluminação branca se apresenta como na Fig. 5a, quando iluminada com luz amarela, se mostraria tal qual a ilustração da Fig. $5 b$.
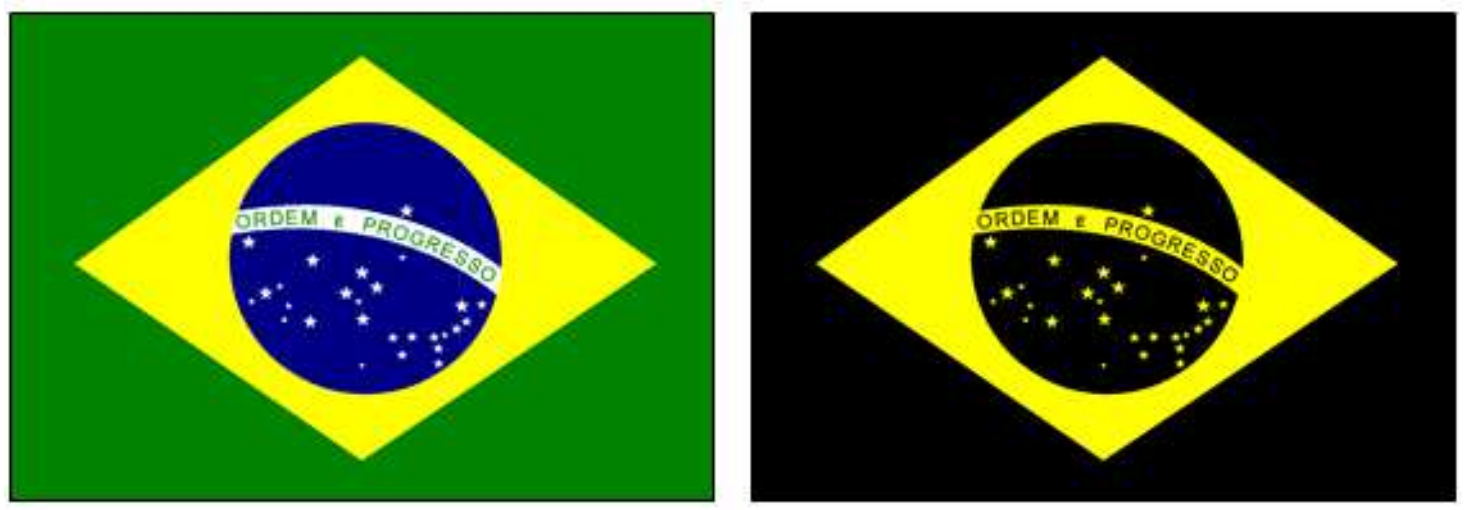

Fig. 5a-Bandeira brasileira iluminada

Fig. 5b-Bandeira brasileira iluminada com luz branca. com luz amarela.

Fonte: Elaborado pelos autores (2016).

Nessa perspectiva, a prova da SBF-MNPEF, no ano de 2015, aplicou uma situação bem semelhante às questões apresentadas anteriormente, conforme o registro a seguir: 
As cores-luz primárias são Vermelho, Verde e Azul. As combinações de pares dessas cores em intensidades iguais produzem as cores-luz secundárias: Ciano (Verde + Azul), Amarelo (Vermelho + Verde) e Magenta (Vermelho + Azul). A luz Branca é a combinação das três cores. As cores dos objetos que enxergamos são devidas às reflexões e absorções seletivas das cores-luz primárias. Por exemplo, um objeto vermelho sob uma luz Branca, absorverá as cores Verde e Azul e refletirá o Vermelho. Um objeto Preto absorverá todas as três cores. Nas cantinas italianas, sob a incidência de luz Branca, é comum vermos as mesas cobertas com toalhas quadriculadas com as cores da bandeira italiana, ou seja, pequenos quadrados com as cores Vermelho, Verde e Branco. Um proprietário quis dar maiores efeitos visuais e iluminou o ambiente exclusivamente com luz Magenta. As cores dos quadriculados das toalhas, Vermelho, Verde e Azul, sob essa iluminação são vistas respectivamente: [...].

Apesar da questão ter invertido a ordem das cores da bandeira italiana e ter se equivocado quando menciona que os "quadriculados das toalhas são vermelho, verde e azul", em vez de verde, branco e vermelho (Fig. 6a) - cores corretas presentes na bandeira da Itália - a resposta dada a esta questão leva em consideração, como ilustra a Fig. 6b, a ordem correta das cores dessa bandeira e não a ordem apresentada na descrição da questão.

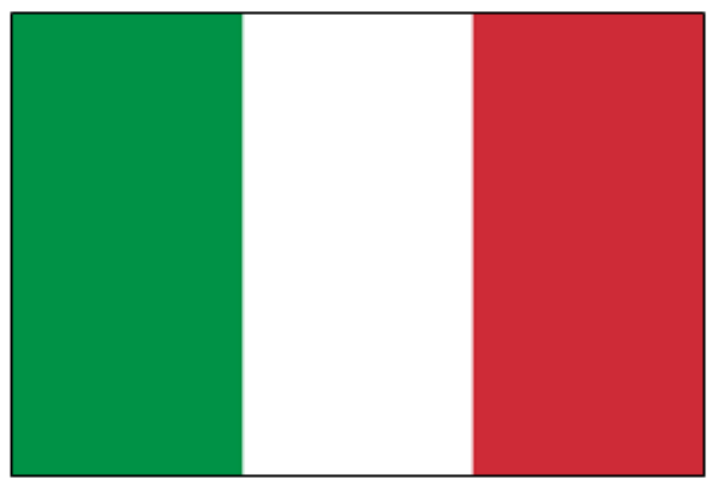

Fig. 6a-Bandeira italiana iluminada com luz branca.

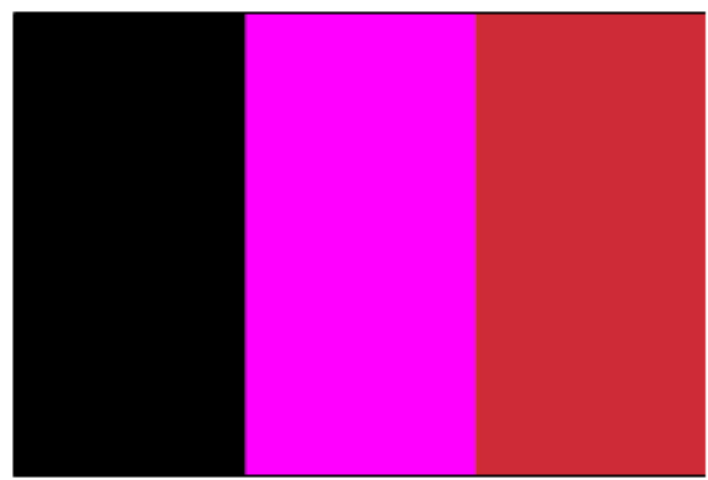

Fig. $6 b-$ Bandeira italiana iluminada com luz magenta.

Fonte: Elaborado pelos autores (2016).

Os materiais que tratam desta questão em particular, juntamente às simulações que serão descritas a seguir, constituíram a base para a formulação da problemática que norteou o desenvolvimento desta análise, constituindo a seguinte questão norteadora: "Quais as cores da bandeira brasileira em diferentes cenários de iluminação?"

Para responder à questão suscitada, foram realizados experimentos, que também serão descritos no transcorrer do artigo, e que possibilitaram, em comparação com o material consultado, a decisão da explicação mais compatível ao questionamento. 


\section{As simulações no estudo das cores}

Buscando observar as possibilidades para o visual da bandeira brasileira quando iluminada com luzes de diversas cores, como sugerem as questões analisadas, foram utilizadas mídias educacionais no formato digital, oriundas do projeto "Acessa Física" através do Software "Cores-Óptica".

Esse projeto foi criado a partir do Edital 01/2007, do Ministério da Educação e do Ministério da Ciência e Tecnologia, com o objetivo de escolher e financiar programas de produção de conteúdos educacionais digitais para as disciplinas de Física, Química, Biologia, e outras, também incluídas no Ensino Médio. A instituição que propôs o projeto foi o Instituto Brasileiro de Educação, Tecnologia e Formação a Distância - IBTF, uma organização da Sociedade Civil de Interesse Público, com grande experiência em programas de educação a distância, uso e desenvolvimento de tecnologias educacionais (BRASIL, 2009).

O recurso educacional intitulado Cores apresenta alguns conceitos básicos da Óptica, como composição de cores, subtração de cores, sistema primário e sistema secundário. Nele, está constituído um teste que visa ilustrar e exemplificar esses conceitos, e que apresenta duas simulações. Na primeira, pode-se compor cores a partir de fontes luminosas nas cores primárias, e, na segunda, explorar os fenômenos de reflexão e absorção da luz por pigmentos.

Na simulação "Formação de cores pelo método aditivo" (RGB) é possível observar a cor resultante das luzes incidentes sobre o anteparo branco. Uma visão geral dessa simulação é apresentada na Fig. 7a, e um exemplo de seu funcionamento pode ser visto na Fig. 7b.

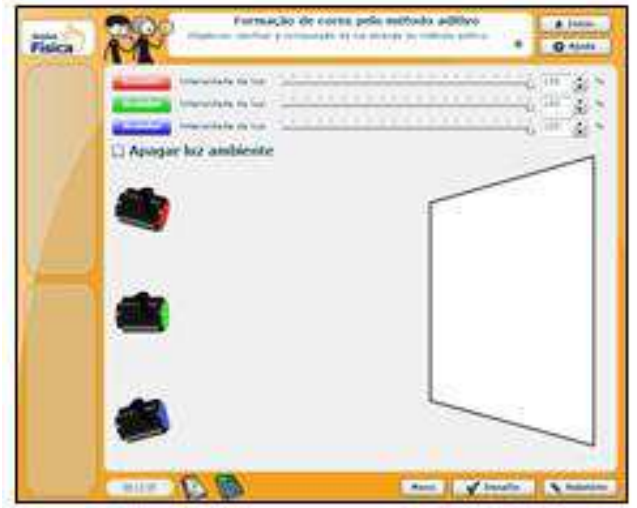

Fig.7a - Visão geral da simulação RGB.

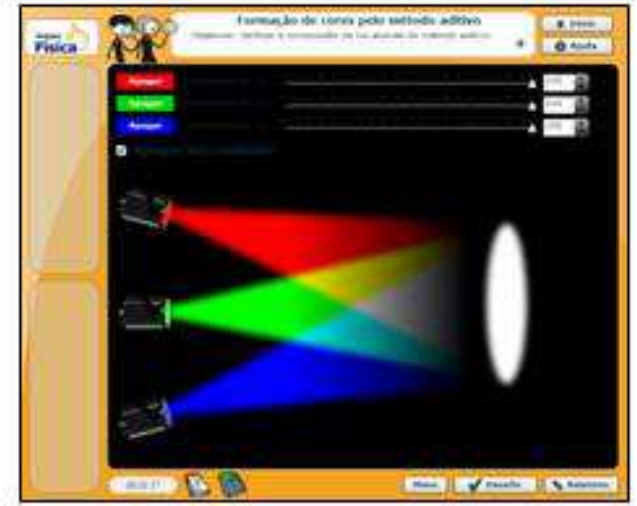

Fig.7b-Exemplo sistema RGB.

Fonte: BRASIL (2010) Captura de tela adaptado do software Cores.

Já na simulação "Formação de cores pelo método subtrativo" (CMY) observam-se os fenômenos de absorção e reflexão da luz pelos pigmentos de cores Ciano, Magenta e Amarelo, que são utilizados como cores primárias no sistema subtrativo de cores.

Objetivando testar a questão proposta por Newton, Helou e Gualter (2010) a partir desta simulação (Fig. 8a), o anteparo foi colorido com o pigmento amarelo - remetendo a 
seção de mesma cor na bandeira do Brasil - e na Fig. 8b, iluminou-se o mesmo anteparo utilizando um filtro de luz verde, com ênfase para a reflexão da luz verde pelo pigmento amarelo. Em seguida, trocou-se o filtro verde pelo vermelho e observou-se que o pigmento amarelo também refletiu a luz vermelha, como mostra a Fig. 8c.
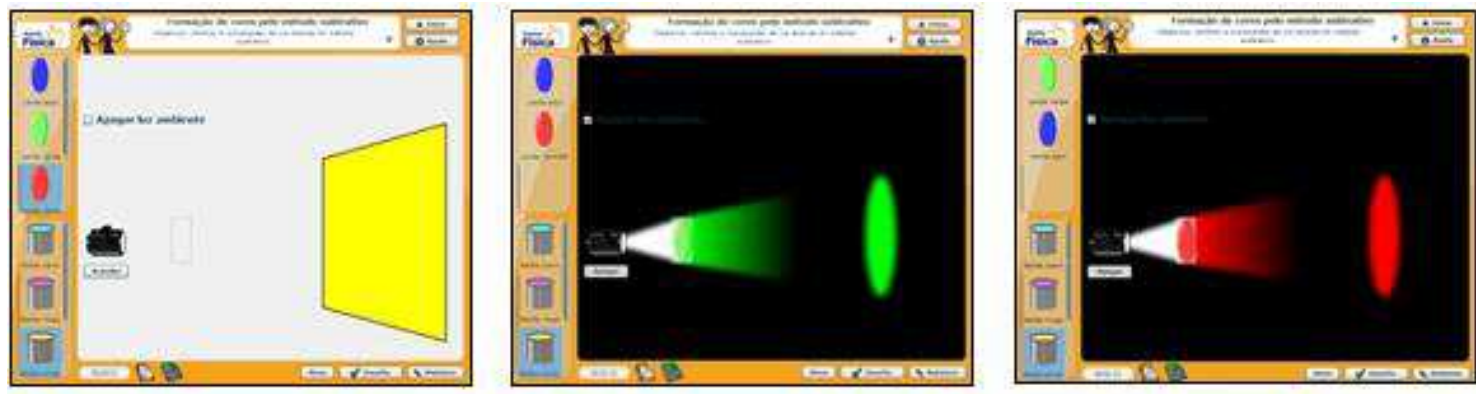

Fig. 8a-Anteparo amarelo. Fig. $8 b$ - Tela amarela

Fig. $8 c$ - Tela amarela iluiluminada com luz verde. minada com luz vermelha.

Fonte: BRASIL (2010) Captura de tela adaptado do software Cores.

Nessa perspectiva, foi possível encontrar uma resposta diferente da proposta por Newton, Helou e Gualter (2010) como ilustram as Fig. 9a e 9b, respectivamente.

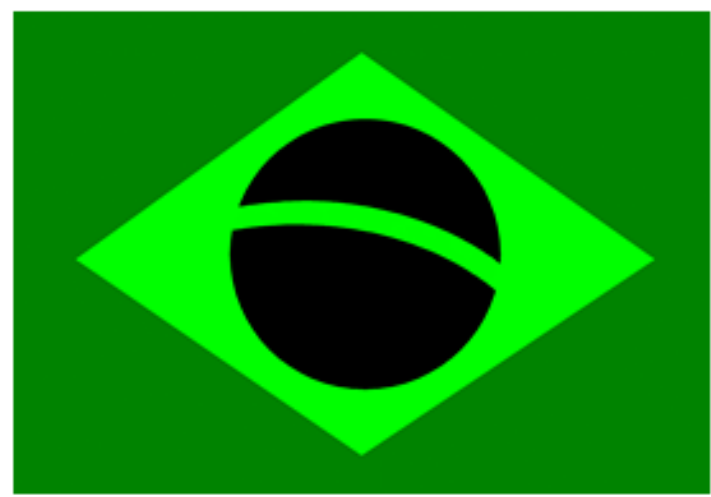

Fig. 9a-Simulação bandeira brasileira iluminada com luz verde.

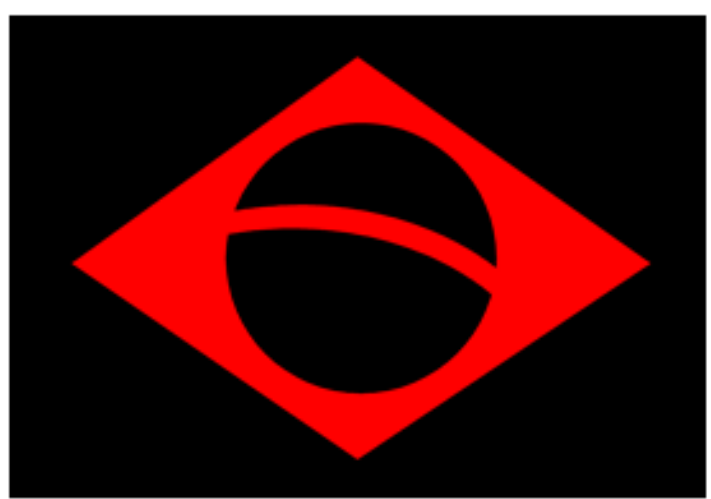

Fig. $9 b$ - Simulação bandeira brasileira iluminada com luz vermelha.

Fonte: Elaborado pelos autores (2016).

Ambas as figuras mostram que o pigmento de cor amarela refletiu tanto a luz verde quanto a luz vermelha. De acordo com Costa (2014), a diferença de tonalidade do pigmento verde na Fig. 9a se deve ao fato de que o pigmento verde do retângulo apresenta em sua composição o pigmento preto responsável por deixar a tonalidade mais escura. Assim, essa parte da bandeira deve absorver um pouco da radiação verde, enquanto que o pigmento amarelo do losango não tem preto em sua composição, logo, nenhuma parte da radiação verde é absorvida. 
Para a questão indicada por Máximo e Alvarenga (2011) não foi possível testar através do aplicativo, pois a simulação limita-se a apresentar apenas as luzes e os pigmentos primários. Nesse caso, optou-se por conduzir uma analogia em relação à questão indicada pela SBF-MNPEF. Conforme esta indicação, ao ser iluminada com luz amarela - luz de cor secundária, composta pela combinação de luzes nas cores verde e vermelha - a bandeira brasileira deveria se apresentar como mostra a Fig. 10, e não como indicam os autores Máximo e Alvarenga (2011), pois a parte verde da bandeira, pigmento secundário, refletiria a faixa de frequência correspondente ao verde da luz amarela.

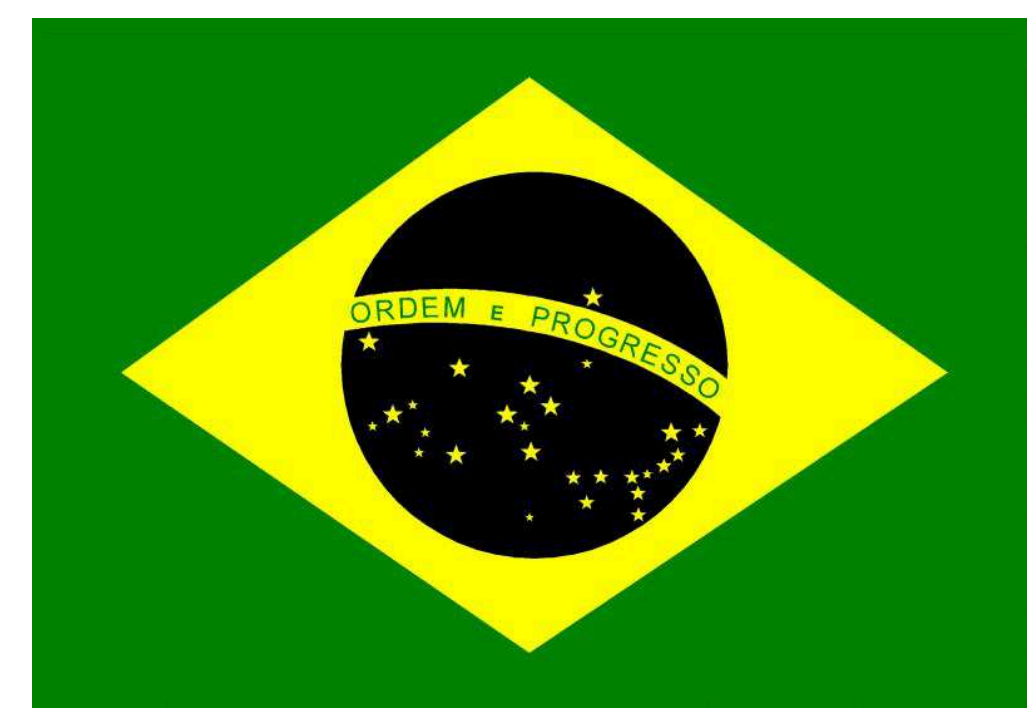

Fig. 10 - Bandeira brasileira sob iluminação amarela, analogia com SBF-MNPEF. Fonte: Elaborado pelos autores (2016).

\section{Descrição do experimento}

O ambiente para a realização dos experimentos propostos foi uma sala totalmente escura, onde a bandeira brasileira constituiu um anteparo durante a observação. Esse anteparo recebeu iluminação por diferentes cores, enquanto foi fotografado para o registro do efeito visual da interação de cada cor (luz) com a pigmentação do tecido.

Para os experimentos, utilizou-se apenas uma bandeira do Brasil, de tamanho pequeno e confeccionada em tecido; três lâmpadas incandescentes com filtros de luz nas cores amarela, verde e vermelha (como ilustra a Fig. 11); conexão elétrica para as lâmpadas e uma câmera fotográfica. 


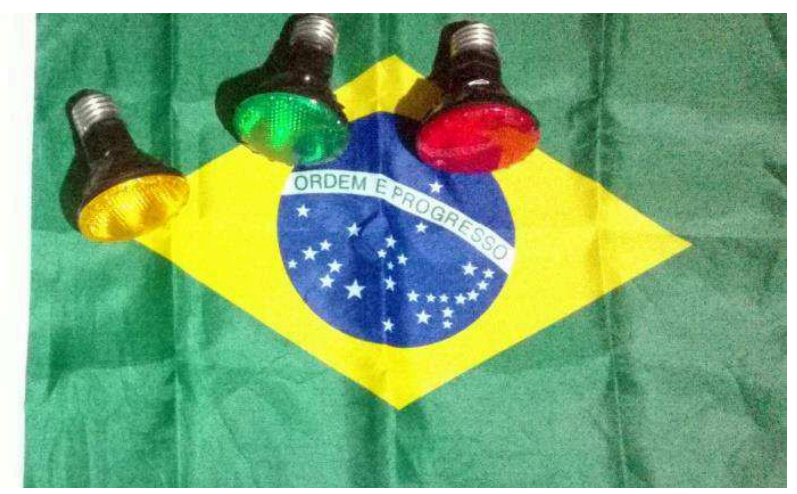

Fig. 11 - Materiais utilizados. Fonte: Elaborada pelos autores.

\section{Resultados}

A questão proposta por Newton, Helou e Gualter (2010) traduz uma situação hipotética, em que o tecido da bandeira é considerado puramente pigmentado, isto é, feito ou tingido por tinta sem traços de outros pigmentos, porém, de acordo com Costa (2014), isso não ocorre, pois, na realidade, em cada parte dela encontra-se uma mistura de outros pigmentos.

Em suas respostas, os autores não levam em consideração o sistema de formação de cores CMY, no qual, o pigmento de cor amarela absorve a luz azul e reflete tanto as luzes de cor verde, quanto as de cor vermelha. Quando o autor não menciona outras possíveis situações, em que objetos podem ser iluminados com luz dicromática, por exemplo, ele corre o risco de deixar o aluno condicionado a pensar que, se um objeto de uma cor qualquer for iluminado com uma luz de cor diferente da original (ou seja, distinta da iluminação solar ou luz branca), sempre se apresentará preto.

Fazendo um comparativo para a primeira situação proposta, - em que a bandeira foi iluminada com luz verde - percebe-se uma divergência quanto aos resultados apresentados por Newton, Helou e Gualter (2010); pela simulação CMY; e pelo experimento I, como mostram as Fig. 12a, 12b, e 12c, respectivamente.

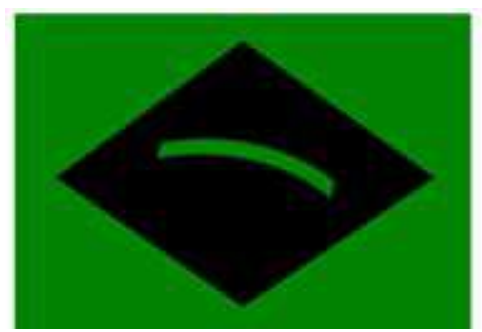

Fig. $12 a-$ Resposta de

Newton, Helou e Gualter (2010).

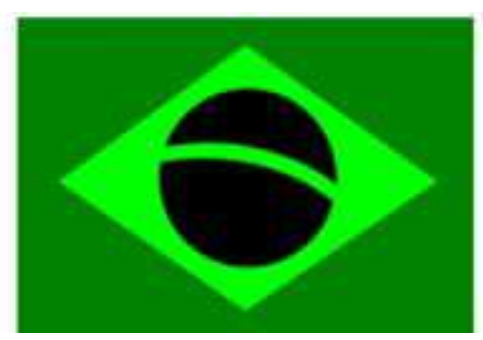

Fig. 12b-Resposta usando a simulação CMY.

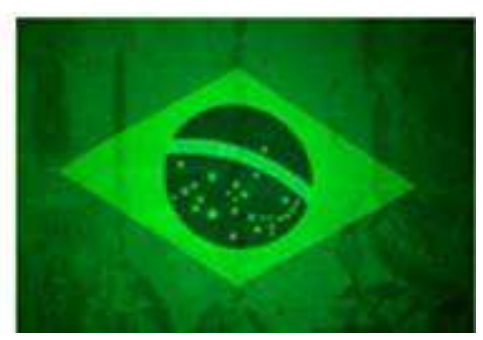

Fig. 12c-Resposta do experimento $I$.

Fonte: Elaborado pelos autores (2016). 
No primeiro experimento, em que a bandeira foi iluminada apenas com luz verde - e que remete a questão proposta por Newton, Helou e Gualter (2010) - o visual da bandeira ficou como mostra a Fig. 12c. Nesse experimento, observou-se que o pigmento verde do retângulo na bandeira permaneceu verde, visto que refletiu a frequência da luz verde incidente, porém, não refletiu toda a radiação, pois o pigmento verde constituinte dessa parte da bandeira possui a adição do pigmento preto para deixar a tonalidade mais escura, como indicado por Costa (2014), e que é responsável pela absorção de uma quantidade da radiação verde.

A parte amarela ficou esverdeada, evidenciando que, ao interagir com a luz verde incidente, esse pigmento refletiu a frequência correspondente ao verde, como indica o sistema de formação de cores CMY. A tonalidade do verde refletido corresponde à reflexão da faixa de frequência da radiação verde incidente.

A parte azul da bandeira se apresentou preta, uma vez que, absorveu toda a radiação incidente e as partes brancas (estrelas e faixa central do círculo) são percebidas na cor verde, pelo fato de conseguirem refletir qualquer faixa de frequência do espectro visível.

Para a segunda situação analisada, na qual a bandeira foi iluminada com luz vermelha, o comparativo entre os resultados em Newton, Helou e Gualter (2010); na simulação CMY; e no experimento II, também apontou divergência nos resultados, como mostram as Fig. 13a, 13b e 13c, respectivamente.

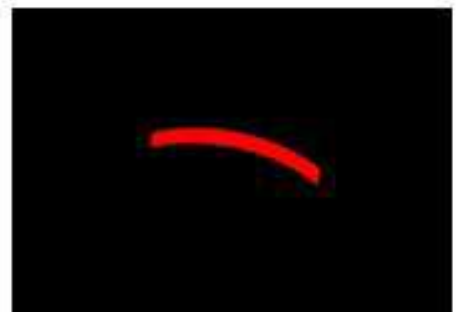

Fig. $13 a$ - Resposta de

Newton, Helou e Gualter (2010).

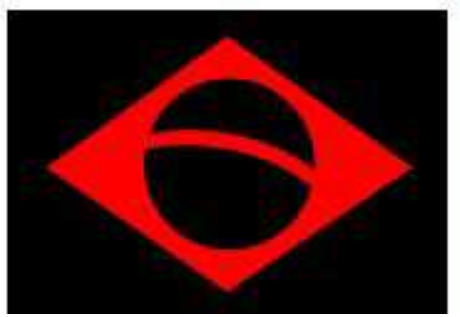

Fig. 13b-Resposta usando a simulação $C M Y$.

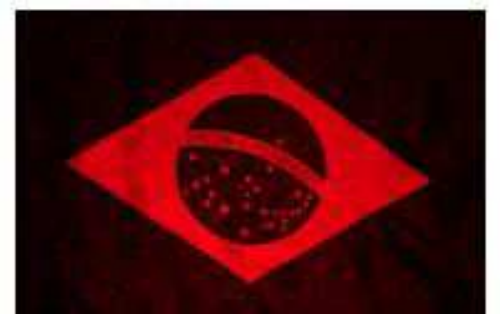

Fig. $13 c-$ Resposta do experimento II.

Fonte: Elaborado pelos autores (2016).

Com relação ao segundo experimento, - no qual a bandeira foi iluminada apenas com luz vermelha - também em referência à questão proposta por Newton, Helou e Gualter (2010), a bandeira se apresentou como mostra a Fig. 13c. Nesse experimento, constatou-se que a parte verde da bandeira se apresentou preta, ao absorver a radiação vermelha incidente.

A parte amarela, por sua vez, se mostrou vermelha por causa de sua capacidade em refletir também a frequência correspondente à cor vermelha, como é descrito no sistema de formação de cores CMY. O círculo azul ainda se apresentou preto, devido à absorção da radiação incidente. A faixa branca, assim como as estrelas, se apresentou vermelha, pois, como já foi dito, são capazes de refletir qualquer frequência dentro do espetro visível. 
Na questão proposta por Máximo e Alvarenga (2011) discute-se a luz amarela como sendo monocromática e, portanto, uma luz primária, não composta pela superposição das luzes verde e vermelha, como sugere o sistema de formação de cores RGB, mencionado anteriormente. Sua resposta mostra que a luz amarela só pode ser refletida pelos pigmentos amarelo e branco.

Esta resposta contraria a resolução apresentada pela SBF, que nos mostra o pigmento vermelho da bandeira italiana sendo refletido normalmente sob iluminação magenta, ao contrário do preto sugerido pelos outros autores. Isso se deve ao fato da luz magenta ser uma cor de luz secundária, formada pela superposição das luzes vermelha e azul, como indica o sistema de formação de cores RGB. Então, ao se incidir luz magenta em um tecido pigmentado de vermelho, este refletirá a componente vermelha da luz magenta e, portanto, será visto como vermelho.

Da mesma forma, ao ser iluminada com luz amarela dicromática (verde e vermelha), analogamente a questão da SBF, a bandeira brasileira deveria se apresentar como mostra a Fig. 14b e não como indica Máximo e Alvarenga (2011), pois a parte verde da bandeira também refletiria a faixa de frequência correspondente ao verde da luz amarela.

Fazendo um comparativo entre os resultados apresentados por Máximo e Alvarenga (2011), pela SBF-MNPEF e pelo experimento III, quando considerada a terceira situação proposta (em que a bandeira foi iluminada com luz amarela) ainda ocorre divergência nos resultados, como mostram as Fig. 14a, 14b e 14c, nesta ordem.

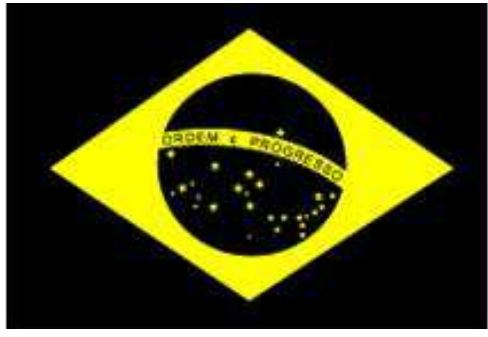

Fig.14a - Resposta de Máximo e Alvarenga (2011).
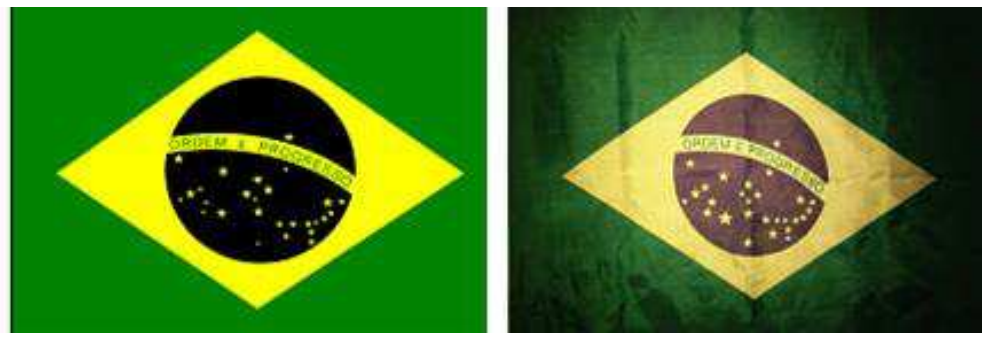

Fig.14b - Resposta da Fig.14c - Resposta do , analogia com a SBF- perimento III. MNPEF.

Fonte: Elaborado pelos autores (2016).

No terceiro e último experimento, em que a bandeira foi iluminada com luz amarela, remetendo a questão proposta por Máximo e Alvarenga (2011), o visual da bandeira fícou como mostra a Fig. 14c.

Nesse experimento, verificou-se que a parte verde da bandeira permaneceu verde, significando que a luz amarela é composta por uma faixa de frequência que envolve as frequências da cor verde, como sugere o sistema de formação de cores RGB. Sendo assim, ao 
receber essa radiação, o pigmento verde absorveu a faixa de frequência da radiação correspondente ao vermelho e refletiu a faixa de frequência referente à cor verde, de acordo com o sistema subtrativo de formação de cores CMY.

Nesse caso, enxergamos apenas o verde, pois o vermelho foi absorvido pelos pigmentos. Como já foi mencionado, a sensação de cor amarela no olho humano se dá pela ativação de cones que recebem raios de luz com frequências correspondentes ao verde, e de cones que recebem frequências de luz correspondente ao vermelho, nas mesmas proporções de intensidade.

A parte amarela da bandeira continuou na mesma cor, já que a luz incidente também é amarela. Nesse caso, ocorreu o processo mais comum da percepção da cor, em cujo, um objeto que recebe luz de sua própria cor será visto como se estivesse sob iluminação branca. $\mathrm{O}$ círculo azul da bandeira se apresentou preto, denotando que o pigmento azul absorveu a radiação amarela, pois não havia, nesse caso, uma faixa de frequência que os pigmentos pudessem refletir.

Por último, a faixa branca e as estrelas da bandeira se mostraram amarelas, significando que essas partes refletiram a faixa de frequência da cor amarela, como esperado, visto que o branco é o resultado da superposição de todas as cores do espectro visível, e pode, deste modo, refletir qualquer frequência dentro dessa faixa.

\section{Considerações finais}

O experimento realizado com a bandeira do Brasil foi bastante esclarecedor e possibilitou testar as sugestões dos autores citados anteriormente, de modo a visualizar o aspecto da bandeira quando esta era iluminada exclusivamente com luz em uma cor específica. Este experimento, realizado em condições específicas de iluminação, demonstrou que objetos de uma determinada cor podem refletir cores diferentes da sua cor de origem, em outros termos, distinta da cor em que se encontra sob iluminação branca.

Esses objetos, ao serem submetidos à luz de diversas cores, são capazes de refletir parte da frequência emitida pela fonte luminosa, que compõe a frequência de sua cor de origem, ou seja, na interação da luz com os pigmentos do objeto, ocorre a reflexão das frequências da cor de determinada parte do objeto, e absorção das frequências que estão fora de sua composição.

Para as situações dos experimentos I e II, nos quais a bandeira foi iluminada apenas com luzes verde e vermelha, respectivamente, conforme as propostas de Newton, Helou e Gualter (2010), constatou-se que a explicação dada por estes autores não condiz com a realidade dos fenômenos ópticos, tendo em vista que eles ignoram os efeitos causados pelas luzes verde e vermelha no pigmento de cor amarela, que tem a capacidade de refletir ambas as cores, de acordo com o sistema subtrativo de formação de cores CMY (explicitado pela simulação "Formação de cores pelo método subtrativo"), que prevê os resultados obtidos pelos experimentos. 
Para a situação do experimento III, no qual a bandeira foi iluminada com luz amarela, verificou-se que a explicação de Máximo e Alvarenga (2011) sobre o visual da bandeira brasileira quando iluminada com luz amarela, não é suficientemente adequada para que o aluno possa compreender a óptica das cores presente nesse processo, visto que mencionam que a luz amarela é monocromática, isto é, desconsiderando a possibilidade de uma luz amarela formada pela composição do vermelho com o verde, como indica o sistema aditivo de cores RGB. Desse modo, concluiu-se que o resultado dessa experimentação se aproxima mais da proposta apresentada pela questão da SBF.

Por fim, é importante enfatizar que os experimentos foram decisivos para a resolução desta problemática, pois proporcionaram uma visão mais clara dos fenômenos ópticos envolvidos nas questões estudadas. Nessa perspectiva, tanto o ato da pesquisa, quanto a experimentação voltada ao ensino, têm sua importância na construção da autonomia do estudante, bem como, na qualidade de sua formação, uma vez que, passando por esses processos, o aluno desenvolve habilidades como leitura, compreensão e escrita de textos científicos, articulação de conceitos físicos com situações do cotidiano, entre outros, contribuindo assim para a melhoria do ensino como um todo.

\section{Referências}

BRASIL. Ministério da Educação - Projeto Acessa Física. [S.1], 2009. Disponível em: <http://177.71.183.29/acessa_fisica/index.php/acessafisica/Principal/O-Projeto>. Acesso em: 10 fev. 2016.

BRASIL. Ministério da Educação - Captura de tela adaptado do software cores. [S.1], 2010. Disponível em: <http://177.71.183.29/acessa_fisica/subsites/361/binrelease/AcessaFisica.html>. Acesso em: 10 fev. 2016.

BRASIL. Sociedade Brasileira de Física - Mestrado Nacional Profissional em Ensino de Física. [S.1], 2015. Disponível em:

<http://www.sbfisica.org.br/ mnpef/images/Gabarito_2015/provaMNPEF2015_vfinal.pdf>. Acesso em: 10 nov. 2015.

COSTA, J. R. V. Bandeira Nacional. [S.1], 2014. Disponível em: <http://www.bandeiranacional.com.br/\#cores2>. Acesso em: 10 fev. 2016.

GREF. Grupo de Reelaboração do Ensino de Física. Física Térmica - Óptica. 5 ed. São Paulo: Editora da Universidade de São Paulo, 2011. v. 2.

HALLIDAY, D.; RESNICK, R.; WALKER, J. Fundamentos de Física. 8 ed. Rio de Janeiro: LTC, 2009. v. 4.

HENEINE, I. F. Biofísica básica. 2 ed. São Paulo: Atheneu, 2010. 
LORETO, E. L. S.; SARTORI, P. H. S. Simulação da visão das cores: decodificando a transdução quântica-elétrica. Caderno Brasileiro de Ensino de Física, Florianópolis, v. 25, n. 2, p. 266-286, ago. 2008. Disponível em:

<https://periodicos.ufsc.br/index.php/fisica/article/view/2175-7941.2008v25n2p266/5635>. Acesso em: 06 dez. 2015.

MÁXimO, A.; AlVAREnGA, B. A. Curso de Física. São Paulo: Scipione, 2011. v. 2.

MELO JUNIOR, R. P. Qual é a influência da cor da luz na fotossíntese? Caderno Brasileiro de Ensino de Física, Florianópolis, v. 32, n. 1, p. 287-290, abr. 2015. Disponível em: <https://periodicos.ufsc.br/index.php/fisica/article/view/2175-7941.2015v32n1p287/29048>. Acesso em: 13 jul. 2016.

NEWTON, V. B.; HELOU, R. D.; GUALTER, J. B. Física. São Paulo: Saraiva, 2010. v. 2.

NISHIDA, S. M.; OLIVEIRA, F A. K.; TROLL, J. Como vemos o mundo? A formação da imagem. Botucatu: UNESP, 2008. Disponível em:

$<$ http://www2.ibb.unesp.br/Museu_Escola/2_qualidade_vida_humana/Museu2_qualidade_cor po_sensorial_visao2.htm>. Acesso em: 15 set. 2016.

OKUNO, E.; CALDAS, I. L.; CHOW, C. Física para ciências biológicas e biomédicas. São Paulo: Harper \& Row do Brasil, 1982. 273 p.

SILVA, G. R. História da Ciência e experimentação: perspectivas de uma abordagem para os anos iniciais do Ensino Fundamental. Revista Brasileira de História da Ciência, Rio de Janeiro, v. 6, n. 1, p. 121-132, jan/jun 2013. p. 126. Disponível em:

<www.sbhc.org.br/arquivo/download?ID_ARQUIVO=1005>. Acesso em: 30 ago. 2016. 